\title{
The Repair of a Distal (one - third) Tibial Fracture in a Local Cock (Gallus gallus domesticus)
}

\author{
*Okafor R. O. $\mathbf{S}^{1}$., Onah, J. A ${ }^{1}$, Omamegbe J. O., ${ }^{1}$ Ajagbe O. A., ${ }^{2}$ Ogbe A. $\mathrm{O}^{3}$ and Audu, Z. \\ ${ }^{1}$ Department of Veterinary Surgery, \\ ${ }^{2}$ Veterinary Teaching Hospital, ${ }^{3}$ Department of Veterinary Medicine, \\ University of Abuja. \\ ${ }^{4}$ Vet Care Clinics, Abuja. \\ DOI:10.36108/jvbs/8102.10.0180
}

\begin{abstract}
A local cock(Gallus gallus domesticus) weighing $1.2 \mathrm{~kg}$ and kept as a pet was referred to the Veterinary Teaching Hospital (VTH), University of Abuja (UA) with the chief complaint of right limb lameness for three days. A close observation showed that the limb was dangling and had a fresh cut on the skin at the distal 1/3 of the tibia. The region was swollen and had a light-greenish colour suspected to be a sign of gangrene formation. Radiographic examination of the region confirmed a complete oblique simple fracture of the distal 1/3 of the tibia of the right limb. The cause of the fracture was unknown. Under Xylazine hydrochloride and Ketamine hydrochloride anaesthesia, the fracture was repaired through an open reduction with intramedullary pin. Eleven days post-surgery, the cock was found to bear slight weight on the limb. Clinical examination three weeks post operation showed normal usage of the limb and radiological evidence of good fracture healing. The intramedullary pinning appeared to be effective for the management of this simple tibial fracture in the local cock. This report appears to be the first intensive fracture repair documented in the local cock.
\end{abstract}

Keywords: Fracture. Gallus Domesticus. Open Reduction. Intramedullary Pin

*Corresponding email: richard.okafor@uniabuja.edu.ng.

Tel: $+234(0) 8136520153$

This Paper was accepted on 15th November, 2017 and published 24th April, 2018 


\section{INTRODUCTION}

Orthopaedic problems like fractures, slip tendons and dislocations are relatively common in the local chickens. However, these conditions usually receive little or no medical/surgical attention as such birds are left to roam and at best are occasionally fed and kept for food [1].Bent [2] noted that Gallus gallus is an under-appreciated pet. However, a few people presently keep them as pets because they are educating and entertaining [3]. Certain breeds of these local fowls such as Bantam and Silkies are so docile that they have been recommended as good pets around children with disabilities [3]. Owners usually give such chickens the necessary medical attention regardless of cost because of their emotional attachment to, rather than the economic value of the birds.

The few available reports on fractures in traditional chickens were mainly on birds at point of lay $[4,5]$. These reports emphasized mainly the diagnosis of such fractures and their effects on the husbandry and egg laying capacity of the birds with little or nothing on the management of the fractures $[6,7]$.

Fractures occur in both local and exotic birds regularly but go untreated [8]. This may probably be because of the low economic value of such birds vis-à-vis the cost of treatment and the strenuous, rigorous and protracted processes involved in fracture repair and recovery of treated cases. The methods used for the management of fractures in birds are similar to those used in small animals. These include the use of splints and casts, cerclage wires, external fixators, intramedullary pins and various combinations of any of the above [9, 10] based on the judgment of the surgeon, taking into considerations the peculiar nature of birds especially the anatomy, the orthopaedic instruments and improvised materials available and the prognosis of the case.

Birds have little soft tissues (tendons, ligaments, skin and muscles) and low blood volume. Therefore, aggressive tissue manipulation and moderate bleeding during surgery can compromise tissue perfusion and may be fatal [8]. Fractures in range birds should be managed with caution because compromising optimal function of the wings and the supination and pronation of the limbs may affect their flight and make them susceptible to their predators $[11,12]$. The prognosis of fracture healing is better in birds than in other animals and it is estimated that properly aligned fractures in birds stabilize within 3 to 6 weeks of appropriate surgical management [13]. Intramedullary pinning is credited as one of the best options for management of tibia fractures in companion birds [14].

\section{History and Observations}

A $1.2 \mathrm{~kg}$ pet local cock (Gallus gallus domesticus) was referred to the VTH, UA with the chief complaint of lameness at its right limb, and no history of any vaccination. A close observation of the cock showed that the right limb was lifted, dangling and had a fresh cut on the skin (Plate 1A) at the distal lateral part of the 


\section{Tibial fracture Repair in a Cock}

tibia. The region was swollen and light-green in colour (Plate 1B). This was suspected to be a sign of gangrene formation. The cock showed signs of pain and crepitus on palpation of the region, was alert and in good body condition. The comb and wattles were bright red in colour and succulent. The haematologic parameters were $\mathrm{R} \mathrm{B} \mathrm{C}=2.6 \times 10^{6} / \mu 1, \mathrm{HB}=8.5 \mathrm{~g} / \mathrm{d} 1$, $\mathrm{WBC}=28.9 \times 10^{3} / \mu 1, \mathrm{PCV}=28.5 \%$ while the temperature, heart rate and respiratory rate were $41.6^{\circ} \mathrm{C}, 280 \mathrm{beat} / \mathrm{min}$ and 84 cycles/minutes respectively. The tentative diagnosis following the physical examination was a complete simple fracture of the distal tibia of the right limb. The affected limb was radiographed in the lateral and anterior - posterior planes. The results confirmed a simple, complete, oblique fracture of the distal one third of the right tibia (Plate 2 and 3 ). There was no radiographic evidence that the fractured bones had exited from the skin surface previously. Physically, the wound in the distal aspect of the tibial region was a transverse surface laceration not a piercing wound as would be expected in a compound fracture (Plate 1A).

The cock was administered long acting Oxytetracycline (Kepro, Holland) at a dose of 20 $\mathrm{mg} / \mathrm{kg}$ intramuscularly. It was admitted at the Avian Unit of the animal house, provided with grower smash (Vital feed) and water ad-libitum until 3hours before the surgery. An open reduction and fixation with an intramedullary pin was chosen as the most appropriate treatment module.

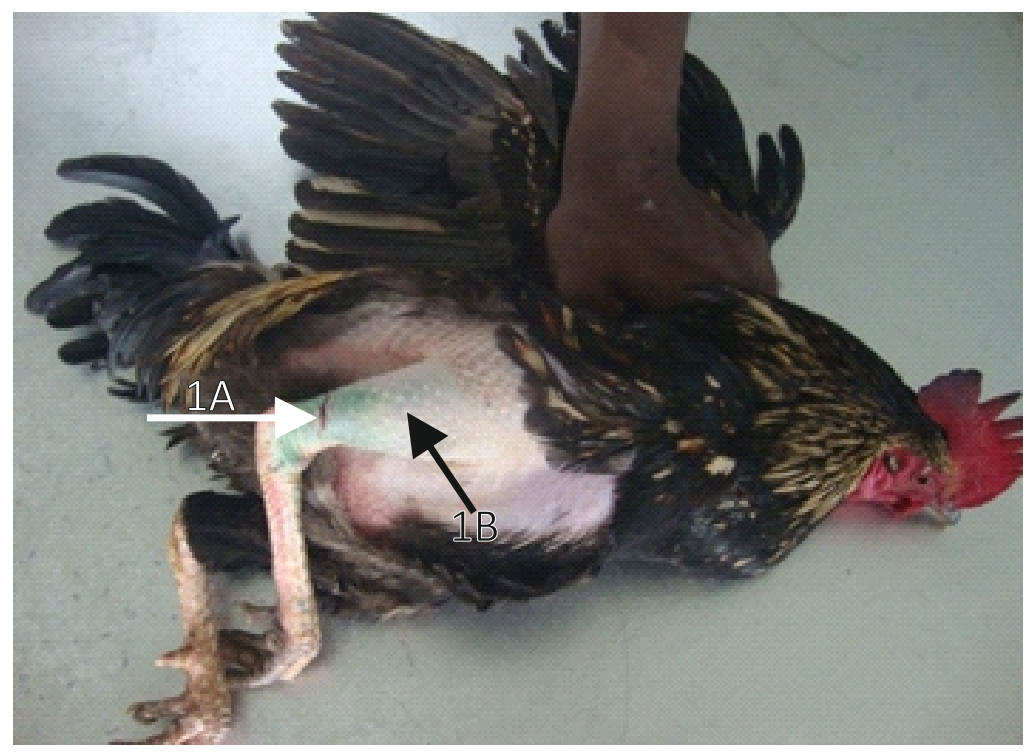

Plate 1: The cock with a fresh wound (A) and light-greenish colour $(B)$ of the skin of the affected limb. Note the knuckling of the digits of the right limb. 


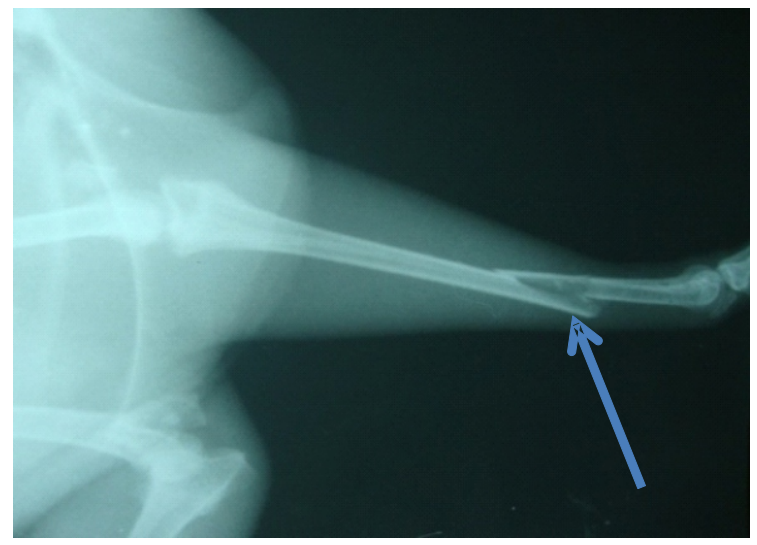

Plate 2: The lateral radiographic view of the cock's right limb, showing an oblique/sliding, simple, complete, fracture (arrow) of the distal $1 / 3$ of the tibia.

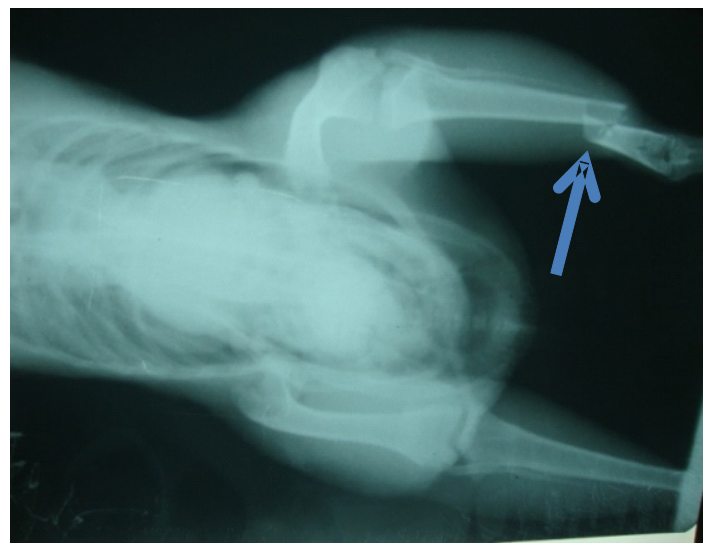

Plate 3: Anterior-posterior radiographic view of the right limb of the cock showing sliding, simple, complete slightly oblique fracture (arrow) of the distal $1 / 3$ of the tibia.

\section{Pre-Operative Preparation and Anaesthesia}

Feathers were plucked circumferentially around the tibia region and up to $2-3 \mathrm{~cm}$ proximal to the stifle joint. The affected limb was prepared aseptically. The cock was sedated with Xylazine hydrochloride (Arendouk, Belgium) at a dose of $4 \mathrm{mg} / \mathrm{kg}$ body weight intramuscularly and anaesthetised with Ketamine hydrochloride (Trittau, Germany) at a dose of $10 \mathrm{mg} / \mathrm{kg}$ intramuscularly. First and second maintenance doses of ketamine hydrochloride were administered intramuscularly using one quarter of the initial dose 12 minutes and 35 minutes after the initial dose, intraoperatively. One millilitre of $20 \%$ Lignocaine hydrochloride (Amritsar, India) was infiltrated deep into the surgical site, five to ten minutes to the commencement of the surgery. The surgical site was draped. The metatarsal region and the phalanges were wrapped in sterile gauze.

\section{Surgery}

A skin incision was made on the cranio-lateral aspect from the mid tibial region to just proximal to the tibio-tarsal joint. The long digital flexor tendon was bluntly separated from gastrocnemius tendon up to the tarsal joint and the fractured bones were exteriorised. An intramedullary pin bent at one end of its length to an angle of about $10^{\circ}$ was introduced proximally into the medullary cavity of the proximal half of the fractured tibia, to exit at the cranial aspect of the tibial table, thus avoiding the stifle joint. The fracture was reduced and its fragments aligned properly. The pin was then normograded into the distal fragment of the fracture to lodge at the medial malleolus of the tibia (Plate 4). An intra-operative radiograph (lateral view) of the reduced and pinned fracture, showed adequate alignment and reduction of the fracture and lodgement of the intramedullary pin on the tibia malleolus (Plate 5). The excess pin was cut off.

The muscles were approximated using size 3/0 absorbable chromic catgut (Life care medical, Anhui, India) in a simple continuous suture pattern. The skin incision was closed using size 3/0 nylon (Agary pharmaceuticals, Giangsu, China) using a simple interrupted suture pattern. Long acting Oxytetracycline (Kepro, Holland) and Piroxicam (Tiangao Pharmaceutical, Hubei, China) were administered intramuscularly at doses of 20 $\mathrm{mg} / \mathrm{kg}$ and $10 \mathrm{mg} / \mathrm{kg}$ respectively. The cock 
recovered uneventfully from anaesthesia three and half hours, post operation. It was discharged three hours later to the owner who was advised to place it on growers mash (Vital feed) and Vitamix (Kepro, Holland) medicated water ad-libitum, while housed in a small (4 feet by 4 feet) enclosure.

The cock was re-presented to the hospital 11 days after surgery and was found to be alert. The sutured site was swollen but the greenish colour noticed prior to the surgery had disappeared. The cock had started bearing weight slightly on the affected limb, although, it was knuckling on its digits. Radiographic examination of the fractured limb at the moment showed very little evidence of bone healing (Plate 6). The owner was advised to supplement the feed with bone meal or calcium gluconate in water and to represent the patient for re-evaluation three weeks later.

On representation of the case as advised, the cock stood and walked normally (Plate 7). There was neither leg carriage on stance or limping on the walk. Radiographic examination of the limb showed bone union and adequate callus formation (Plate 8).

The patient was eventually discharged and the owner advised to ensure limited and guided use of the limb over the next 2-3 months.

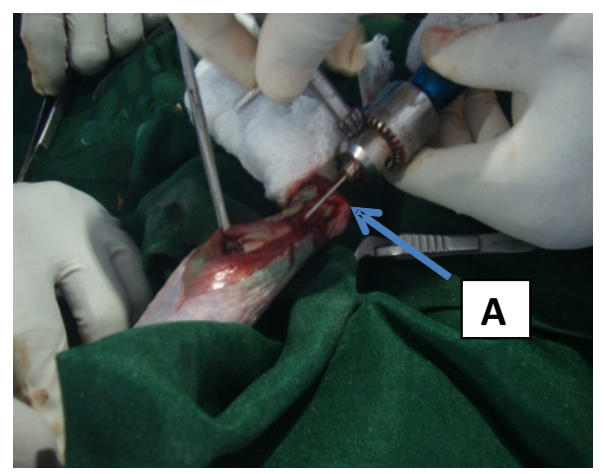

Plate 4: The introduction of an intramedullary pin (A) into the medullary cavity of the proximal half of the tibia

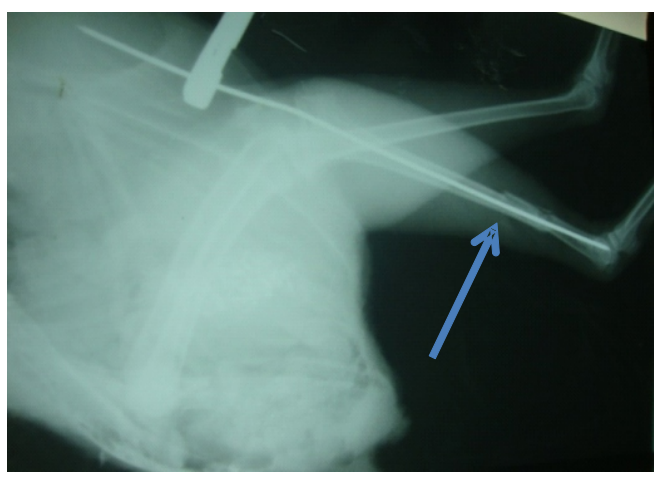

Plate 5: Intra-operative lateral radiographic view of the fractured limb showing the reduced and properly alligned fracture fragments by intramedullary pinning (arrow)

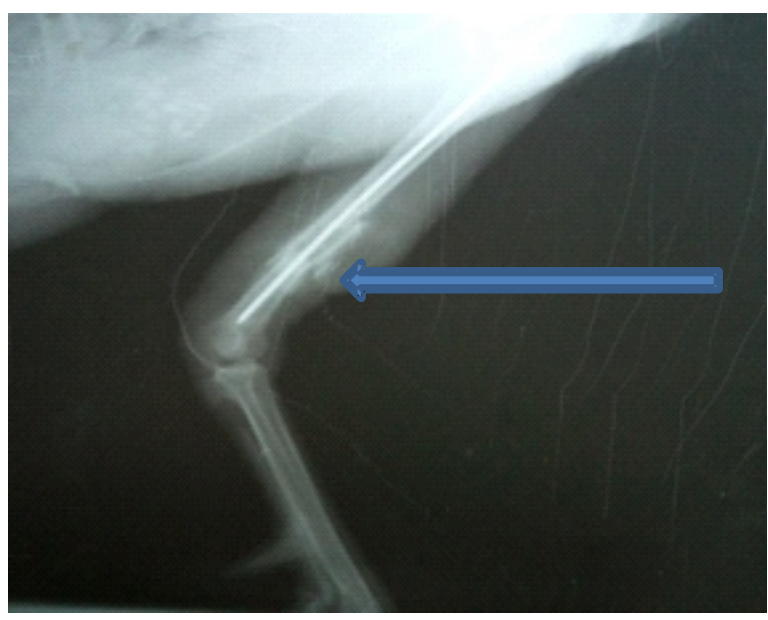

Plate 6: Lateral radiographic view of the fractured limb showing properly alligned fracture fragments by intramedullary pinning but with little or no callus formation 11 days post surgery (arrow)

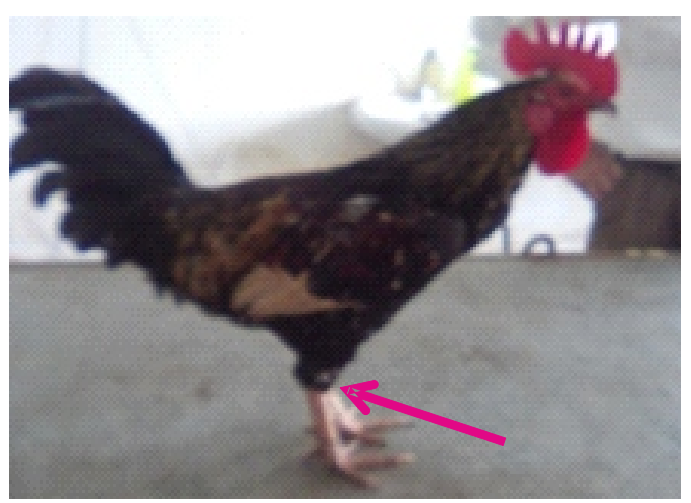

Plate 7: The cock bearing its normal weight on the affected limb with feathers re-grown at the position of the healed wound and repaired fracture, 8 weeks post-surgery. 


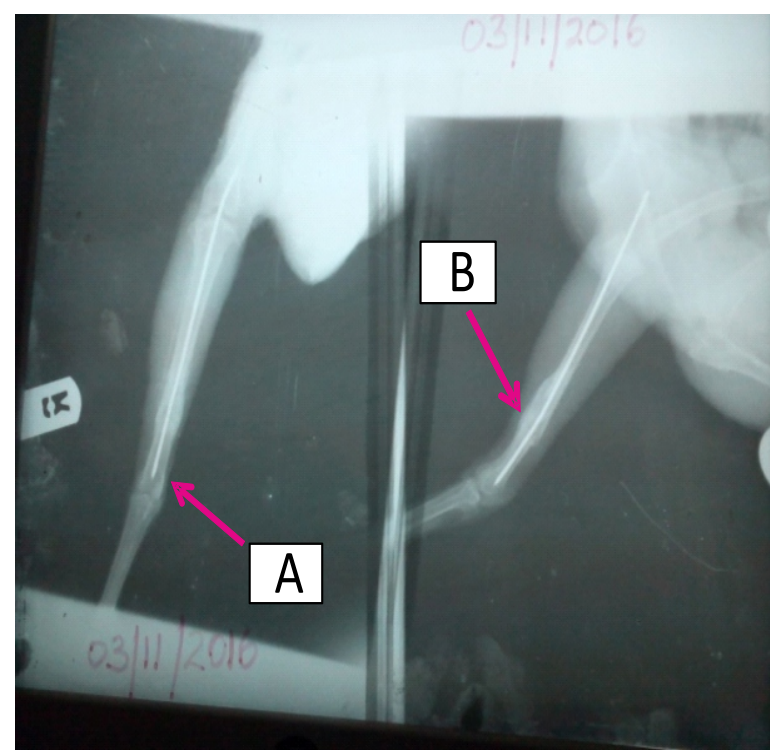

Plate 8: Lateral (A) and anterior-posterior (B) radiographic view of the repaired fracture showing large callus formations (arrowed) of the healed bone 8 weeks post-surgery

\section{DISCUSSION}

The incidence of fractures in chickens (poultry) is low and the few cases reported were pathologic in origin and associated with calcium deficiency, bone malformation and disproportionate weight [15]. Other reports in commercial and non-commercial laying birds described the diagnosis of these pathologic fractures with no reference made to traumatic fractures or their management $[4,15]$. Richards [16] recently suggested that local birds with fractures should be managed by cage rest or should otherwise be euthanized. The rational for this is probably due to the low economic values of these local birds when considered alongside the strenuous and rigorous processes involved in the management of fractures.

Currently, pet chicken clientele is very low and the few available agree that the cost of intensive medical or surgical care such as required for fracture management in these birds is justifiable only on emotional grounds rather than the bird's economic value [2].

A combination of Xylazine and Ketamine hydrochloride at dosage ranges of $2-10$ $\mathrm{mg} / \mathrm{kg}$ body weight and $10-50 \mathrm{mg} / \mathrm{kg}$ body weight have been adjudged the best anaesthetic protocol in several avian breeds like chickens, budgerigars, pigeons and ostriches [7, 17, 18]. These dosage levels had recovery periods ranging from 60 - 113 minutes, depending on the induction dosages. The induction doses of Xylazine and Ketamine used in this case were in the medium ranges of those referred to above and certainly did not effect enough narcosis long enough for a surgical intervention. The experience from handling this case suggests that higher doses of both Xylazine and Ketamine as suggested by Uzma et al, [17]; Clark et al, [7] and Gandomani et al, [18] are required to enable the execution of major surgical interventions in the local Nigerian chickens particularly in one person practices as this could avoid the need for supplementation of the anaesthesia during the course of the surgical procedure. The prolonged recovery period of the cock is thought to be due to the supplementary doses of Ketamine administered intra-operatively.

Due to the low blood volume of avian species, the strict limitation of blood loss during surgeries through the adoption of bloodless techniques e.g. blunt muscle separations, tissue separation with gauze, prompt arrest of any form of bleeding was used/observed. This helped in the preservation of the blood volume 
and is critical to their survival during surgical procedures and to the eventual outcome of the cases [8]. Other positive post-operative responses such as the resolution of the gangrenous changes noticed around the fractured site prior to surgery may be attributable to the re- institution of adequate blood supply to affected tissues, following the surgical treatment.

The intramedullary pinning approach used in this case was considered based on the tiny cortices of the avian tibia, the open skin wound and the position of the fracture. Intramedullary pinning has the advantage of neutralizing bending forces and enables adequate bone alignment [19] More so, the relative size of the IM pin that fitted the size of the cortices of the bird was available and affordable [20]. The open reduction facilitated direct traction to the bone thereby reducing excessive trauma to the soft tissues and equally created room for proper cleaning of the fracture site, removal of debris and necrotic tissue that might have delayed bone healing [14]. Internal fixation procedures (in this case intramedullary pinning) appeared the best option for the management of tibial fractures in birds [21]. This is because generally the fold of skin that extends from the inguinal region to the stifle region obviates the use of external coaptations except perhaps the use of types I or II Elmer Kirshner apparatus/splintage [22] using light weight material like fibre-glass [23]. The use of fiberglass in this case was not possible due to its unavailability. The difficulty in finding a bone plate of appropriate size that can fit the brittle cortex of avian bone [23], coupled with longer anaesthetic time, larger opening of the fractured site and aggressive tissue manipulation that are required for bone platting, which might consequently compromise the blood vessels and prolong healing time overruled its consideration [23, 24].

In conclusion, Intramedullary pinning was effective in the management of this simple tibial fracture in a local cock. This was enhanced by minimal tissue trauma and blood loss; and strict adherence to aseptic procedures.

\section{REFERENCES}

1. Dohner, J. V (2001). The Encyclopaedia of Historic and Endangered Livestock and Poultry Breeds. Yale University Press. ISBN 030013813X.

2. Bent, N (2002). Gallus gallus: An underappreciated pet. American Journal of Federation of Aviculture: Watch Birds. 2 (2):1790-3534.

3. Herrema, M (2014). Chickens 'closer to dinosaurs' than other birds. University of Kent Retrieved 20 June 2016.

4. Gregory, N. G., Wilkins, L. J., Eleperuma, A. D., Ballantyne, A. J. and Overfield, N.D. (1990). Broken bones in domestic fowls: Effect of husbandry system and stunning method in end-of-lay hens. British Poultry Science. 31:59-69.

5. Gregory, N. G., Wilkins, L. J., Alvey, D. M. and Tucker, S. A. (1993) Effect of catching method and lighting intensity on the prevalence of broken bones and on 
the ease of handling of end-of-lay hens. Veterinary Records. 132:127-129

6. Budgell, K. L. and Silversides F. G. (2004). Bone breakage in three strains of end-of lay hens. Canadian Journal of Animal Science. 84:745-747.

7. Clark, W. D., Cox, W. R. and Silversides F. G. (2007) Radio density in the central cavity of humeri in high-producing noncommercial laying hens. British Poultry Science,48:647-650.

8. $\quad$ M u h a m mad, T. M ., Muhammad, A. Z., Nasir, M., Arfan Y., Muhammad, S.A., Sajid, U and Maaz, A ( 201015$)$. Intramedullary Fixation Approach to Tibiotarsal Fracture in Ostrich (struthio camelus): Case Report. Open Access Veterinaria, 3(1) Pp. 28-31.

9. Kavanagh M. (1997). Tibiotarsal fracture repair in a scarlet macaw using external skeletal fixation. Journal of Small Animal Practice, 38: 296-298.

10. Helmer, P and Redig P. T (2006). Surgical Resolution of Orthopaedic disorders. Clinical Avian Medicine, 2:761 -774.

11. Lind, P. G, Degenes, L. A., Olson, D. G (1989). Bone cement/polypropylene rod orthopaedics techniques. Journal Association of Avian Veterinarian, 3(4) 203-206.
12. Rough, J C (1980). Avian Orthopaedics; In Kirk R W (Ed). Current Veterinary Therapy VII. Philadelphia. W.B Saunders Co. Pp 662-673.

13. Williams, R. J., Holland, M., Milton, J. L (1987). A comparative study of treatment methods for long bone fractures. Companion Animal Practice, 1(4): 48-55.

14. Redig, P. T (1986): A Clinical Review of Orthopaedic Technique used in the Rehabilitation of Raptors. Proceedings: Students American Veterinary Medical Association Symposium. Pp.8-21.

15. Clark, W. D., Cox, W. R., Silversides, F.G (2008). Bone Fracture Incidence in End-of-Lay High-Producing, Non-commercial Laying Hens Identified Using Radiographs. Poultry Science Association, 87 (10): 1964-197.

16. Richard Jones (2016). Fracture Repair in Backyard Hens. www.avianveterinaryservices.co.u k. Accessed September $26^{\text {th }}, 2016$.

17. Uzma, F. D., Muhammad, A. Muhammad, A. K (2009). Comparison of clinical effects associated xylazine, ketamine, and xylazine-ketamine in cocktail in pigeon (Columba livia), Turkish Journal of Veterinary Animal.33 (5):413-417.

18. Gandomani, M. J., Tamadon, A., Mahdizadeh, A., Attaran, H. I (2009). Comparison of Different Ketaminne-Xylazine Combination for Prolonged Anaesthesia in 
Budgerigars (Melopsittacus undulatus. Scan Online Veterinary Journal. (www.vetscan.co.uk) 4(1): 34 .

19. Levitt, 1. (1989). Avian orthopaedics compendium. Veterinary Continuing Education Practice, 11:899-929.

20. Duerr, R. (2010). Splinting avian fractures. International Bird Rescue Research Centre, Cordelia, CA. $2^{\text {nd }}$ Edition. Pp 1-27.

21. Elkins, A. D., Blass. C. E (1982). Management of Avian Fracture part 2: pins and wires. Veterinary Medicine Small Animal Clinic, 77:825-828.
22. MacCow, D. M (1992). Treatment of fractures in avian species. Veterinary Clinics North America Small Animal Practice, 22 (1):225-238.

23. Westfall, M. L. and Egger, E. L. (1979). The Management of Long Bone Fractures in Birds," Iowa State University Veterinarian, 41 (2): 81-87.

24 Howard, M and Branson, W. R (1994). Orthopaedic surgical technique. In: Avian Medicine, Principle and Application; Branson, W. R., Greg, J. H and Linda, R. H. (Ed.). Wingers Publishing Inc, Lake Worth, Florida. Pp: 1138-1169. 